\title{
Quantified exponence constraints and the typology of exponence
}

\author{
Yifan Yang \\ University of Southern California
}

\section{Introduction}

This paper examines several phenomena that involve one-to-many exponence patterns, aiming at exploring the inherent relations between them, and solving the issues raised by these phenomena. Exponence refers to the mapping of morphosyntactic structure to phonological representations, while exponents are the corresponding phonological materials of a morphosyntactic structure (Matthews 1991:175). In languages, it is not uncommon to see more than one exponent corresponding to a single morphosyntactic feature (or feature bundle). A well-known phenomenon like this is phonologically conditioned suppletive allomorphy (PCSA), where more than one allomorph is listed in the lexicon rather than being derived from a single underlying representation, and the selection is phonologically controlled. Another phenomenon is multiple exponence (ME) (Matthews 1991, Anderson 2001, Caballero and Harris 2012, Harris 2017, among others), which exhibits simultaneous realization of more than one exponent.

PCSA and ME raise several theoretical and analytical issues. For example, are they unrelated phenomena or actually related in certain ways? What grammatical mechanism can give rise to multiple exponence, which involves redundancy and contradicts the economy principle? In previous work, these phenomena are usually discussed separately, but in this paper, I will show that they can be analyzed in a unified way. To solve these issues, three major proposals are made in this paper, including 1) the morphosyntactic information and phonological information are interlinked in the lexicon via correspondence relation, 2) there are two GEN functions, i-GEN and GEN, which operate on different structures and result in two levels of mapping, and 3) there are two quantified exponence constraints governing the quantity of exponents that are realized, and the proposed constraints predict a full typology of exponence.

This paper is organized as follows. Section 2 presents the data and issues; section 3 introduces the proposals, and the newly-introduced mechanism is exemplified in section 4; section 5 performs a test on typological predictions, and section 6 discusses an alternative approach.

\section{Phenomena and issues}

2.1 Highlighted phenomena A well-known phenomenon that exhibits one-to-many mapping between morphosyntactic information and phonological representation is suppletive allomorphy, and a parade example is found in Moroccan Arabic, shown in (1) (Harrell 1962, cited in Mascaró 2007:717).

(1)

\begin{tabular}{|c|c|c|c|c|}
\hline \multicolumn{5}{|c|}{ Moroccan Arabic } \\
\hline & stem & gloss & 3p.sg.m & gloss \\
\hline a. & $x t^{f} a$ & 'error' & $\mathrm{xt}^{\mathrm{f}} \mathrm{a}-\mathrm{h}$ & 'his error' \\
\hline b. & Safu & 'they saw' & fafu-h & 'they saw him' \\
\hline c. & ktab & 'book’' & ktab-u & 'his book' \\
\hline d. & Jaf & 'he saw' & Saf-u & 'he saw him' \\
\hline
\end{tabular}

\footnotetext{
* I am grateful to Rachel Walker, Karen Jesney, and all the other audience at USC PhonLunch for their valuable comments on previous versions of this work. Thanks are also due to the audience at AMP 2017. All the errors are my own.

(C) 2018 Yifan Yang

Proceedings of $A M P 2017$
} 
There are two allomorphs of the third person masculine singular prenominal clitic (3p.sg.m) in this language, i.e. / $\mathrm{h} / \mathrm{and} / \mathrm{-u} /$, listed in the lexicon, and the selection is phonologically controlled. The marker $/ \mathrm{h} / \mathrm{is}$ selected when the stem is vowel-final (e.g. [ $\left.\mathrm{xt}^{\mathrm{f}} \mathrm{a}-\mathbf{h}\right]$ ), while /-u/ is selected if the stem is vowel-final (e.g. ktab-u). Since the allomorphic selection in Moroccan Arabic is determined by phonological optimization, this type of suppletive allomorphy is usually termed as phonologically conditioned suppletive allomorphy (henceforth PCSA) (Carstairs 1988, 1990, among many others).

Another phenomenon that also exhibits one-to-many exponence is multiple exponence (ME) (Matthews 1991, Xu 2007, Caballero and Harris 2012, Harris 2017, among others) which exhibits simultaneous realization of more than one exponent, with Tamazight Berber being a classic example (cited in Xu 2007:84):

\begin{tabular}{llll}
\multicolumn{5}{l}{ Tamazight Berber } \\
\hline person & gender & singular & plural \\
\hline 1 & & dawa- & n-dawa \\
2 & m. & t-dawa-d & t-dawa-m \\
& f. & t-dawa-d & t-dawa-n-t \\
3 & m. & i-dawa & dawa-n \\
& f. & t-dawa & dawa-n-t \\
\hline
\end{tabular}

In Tamazight Berber, certain morphosyntactic features can be realized by more than one form. Take the second person singular for example, the analyses of Noyer (1992), Xu (2007), Xu and Aronoff (2011) suggest that two forms can contribute to the meaning ' $2^{\text {nd }}$ person', i.e. $/ \mathrm{t}-/\left(2^{\text {nd }}\right.$ person $)$ and $/-\mathrm{d} /\left(2^{\text {nd }}\right.$ person, singular $)$, and both forms are compulsory in the surface, though seeming to be redundant (see Noyer 1992 and Xu 2007 for detailed discussion of the markers).

Though PCSA and ME are usually discussed separately, a special case of multiple exponence found in Lower Jubba Maay (Paster 2006, 2010) suggests a close relation between these two phenomena. Some data from Lower Jubba Maay is given in (3) and (4) (Paster 2006:86-87).

Plural marking in Lower Jubba Maay: vowel-final nouns

\begin{tabular}{llll}
\hline & singular noun & plural noun & gloss \\
\hline a. & buundo & buundo-yal & 'bridges' \\
b. & liwa & liwa-yal & 'lions' \\
c. & maða & maða-yal & 'heads' \\
d. & indo & indo-yal & 'eyes' \\
\hline
\end{tabular}

(4)

Plural marking in Lower Jubba Maay: consonant-final nouns

\begin{tabular}{llll}
\hline & singular noun & plural noun & gloss \\
\hline a. & mukulal & mukulal-o, mukulal-yal, mukulal-o-yal & 'cats' \\
b. & eey & eey-o, eey-yal, eey-o-yal & 'dogs' \\
c. & geet & geeð-o, geed-yal, geeð-o-yal & 'trees' \\
d. & hidik & hidið-o, hidig-yal, hidiy-o-yal & 'stars' \\
\hline
\end{tabular}

In this language, plural can be marked by two suffixes, /-o/ or /-yal/, and the distribution of these markers are to some extent phonologically conditioned. More specifically, all the vowel-final nouns take /-yal/ suffix, avoiding /-o/, while there are three ways to form a plural for any consonant-final noun. The most striking property of these data lies in that the two markers can be optionally realized together, shown in (4), and it is viewed as a case of optional multiple exponence (Paster 2010, Caballero and Harris 2012, Caballero and Inkelas 2013).

2.2 Issues raised by these phenomena The phenomena that involve one-to-many mapping between morphosyntactic information and phonological representations raise several theoretical and analytical issues.

First, the existence of ME challenges morphological theory, especially the principle of economy (e.g. Kiparsky 2005). Kiparsky (2005:114) proposes a constraint, ECONOMY, which requires the simplest 
expression be chosen when other things are equal. ECONOMY allows the choice of one allomorph or another in different contexts, just like the case of Moroccan Arabic, but it will always block multiple exponence. Second, in Optimality Theory (OT, Prince and Smolensky 1993/2004), PCSA has been discussed extensively (Mascaró 1996, 2007, etc., see also Nevins 2011, McCarthy 2012 for general discussions), and the conventional approach of analyzing PCSA in OT lists all the allomorphs in the input, demonstrated below (Mascaró 2007:717):

\begin{tabular}{|r|c|c|c|c|}
\hline$/ \mathrm{xt}^{\mathrm{a}} \mathrm{a}-\{\mathrm{h}, \mathrm{u}\} /$ & MAX & DEP & ONSET & NOCODA \\
\hline $\mathrm{xt}^{\mathrm{f}} \mathrm{ah}$ & & & & 1 \\
\hline $\mathrm{xt}^{\mathrm{f}} \mathrm{a} . \mathrm{u}$ & & & $1 \mathrm{~W}$ & $\mathrm{~L}$ \\
\hline
\end{tabular}

One stipulation made in the conventional approach is that each candidate generated by GEN can only contain one of the allomorphs listed in the input. Consequently, no candidates such like [ $\left.\mathrm{xt}^{\mathrm{\zeta}} \mathrm{ahu}\right]$ or [ $\left.\mathrm{xt}^{\mathrm{f}} \mathrm{auh}\right] \mathrm{can}$ be generated. When it comes to Lower Jubba Maay, where the plural marking also involves two forms, no candidate like mukulal-o-yal can be generated, given the current GEN function.

Further, the evaluation of input-output faithfulness is not unproblematic in the conventional approach. The candidates in (5) do not incur any violations of MAX or DEP, which indicates that the 'input' in this tableau is not the one being evaluated by IO-FAITH constraints. Instead, the tableau above assumes that the allomorph selected in the output is only compared with its correspondent in the input, and this assumes the existence of an intermediate representation, different from the actual input $/ \mathrm{xt}^{\mathrm{f}} \mathrm{a}-\{\mathrm{h}, \mathrm{u}\} /$ in tableau (5).

Finally, another issue is whether PCSA and ME can be viewed as related phenomena and whether there is a unified analysis for both of them, since they share certain similarities. If they are related phenomena, what mechanism makes them different? Some previous work seeks solutions that can cover both PCSA and $\mathrm{ME}$, and they try to use different mechanisms to distinguish these two related but different phenomena. For example, in Optimal Interleaving (e.g. Wolf 2008, 2015, Kimper 2009), PCSA and ME are given rise to through different lexical representations. However, the plural marker in Lower Jubba Maay challenges this approach in that the exponents /-o/ and /-yal/ can be selected separately or optionally realized together.

To sum up, both PCSA and ME involve one-to-many mapping between morphosyntactic information and phonological representations, and the existence of ME, especially the special case of Lower Jubba Maay, raises some theoretical and analytical issues. The following section will give a proposal that can lead to a unified account for both phenomena in Optimality Theory.

\section{Proposal}

In order to tackle the issues presented above, this paper claims that 1) the morphosyntactic information and phonological information are stored in the lexicon in an organized way; 2) there are two GEN functions, and the generation of output candidates is viewed as a two-stage process, and 3) there is one more level of faithfulness other than IO-FAITH and the number of exponents that are realized is governed by two newlyproposed faithfulness constraints.

3.1 The organization of the lexicon First, I propose that the lexicon contains morphosyntactic features ( $\mathbf{M}$ information) and corresponding phonological exponents ( $\mathbf{P}$ information), and all the information is organized as a network via correspondence relation (McCarthy and Prince 1995). The notions of morphosyntactic feature and phonological representation are the same as the ones used in Distributed Morphology (Halle and Marantz 1993, Halle 1997), Distributed Optimality (Trommer 2001) and Optimal Interleaving (Wolf 2008, 2015, McCarthy 2012). Different from the previous theories, I assume that there is correspondence relation (McCarthy and Prince 1995) between M information and P information (cf. Walker and Feng 2004, Kimper 2009). The correspondence relation between morphological structure and phonological structure is first proposed in Walker (2000) and Walker and Feng (2004) (the 'Ternary Model'), where the constraint MAX-MP requires that 'every morpheme in the output morphological structure have a correspondent in the output phonological structure' (Walker 2000:88), which is a type of output-output correspondence. Nevertheless, the correspondence between the $\mathrm{M}$ information and $\mathrm{P}$ information in the 
current proposal is encoded in the lexicon, which is similar to Kimper (2009)'s proposal. Therefore, the lexicon is organized as a network by connecting the features and exponents via correspondence relations, which can be illustrated below:
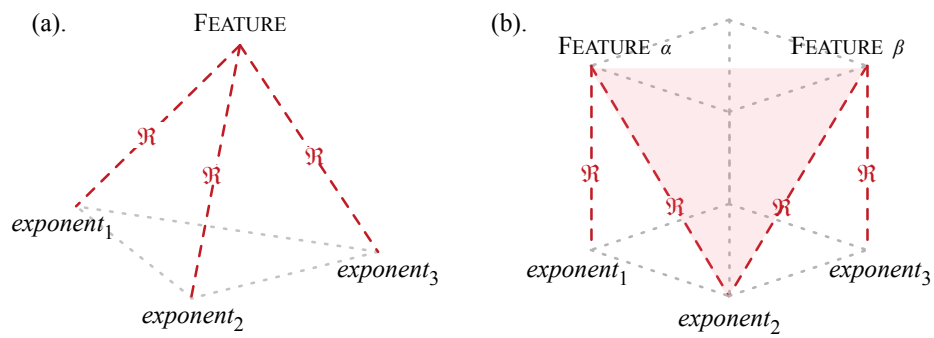

In this representation, if more than one exponent is used to express a morphosyntactic feature (e.g. 6a), then there is one-to-many mapping between $\mathrm{M}$ information and $\mathrm{P}$ information in the lexicon. Conversely, if more than one morphosyntactic feature corresponds to the same exponent (e.g. exponent ${ }_{2}$ in $6 \mathrm{~b}$ ), we say there is many-to-one mapping between $\mathrm{M}$ information and $\mathrm{P}$ information, which is equivalent to the familiar term portmanteau morph in morphology (cf. Matthews 1991).

To better illustrate this point, the representations of the feature bundle $\left\{3^{\text {RD }}\right.$ PERSON.MASC.SINGULAR $\}$ ( $\{3$ P.M.SG $\}$ ) in Moroccan Arabic and the feature $\{$ PLURAL $\}$ in Lower Jubba Maay, as well as their corresponding phonological exponents, are given in (7).
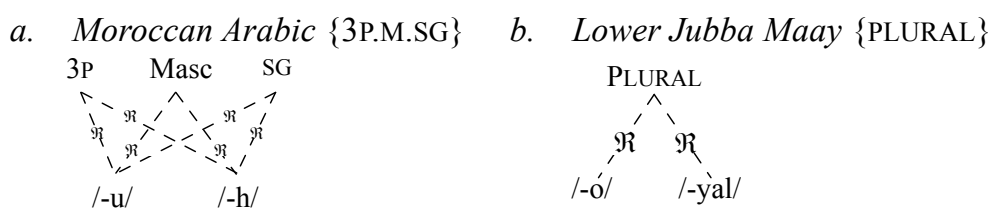

The structures shown in (7) that contain all the relevant $\mathrm{M}$ and $\mathrm{P}$ information required by the meaning are called the Lexical Representation (LR). For example, if the meaning requires 'third person singular masculine', then the relevant information that can express this meaning will appear in the LR (namely 7a). Note that the LR is not equal to the lexicon. Instead, the LR is only a part of the network of the lexicon, and it is selected in order to express the required meaning.

The importance of distinguishing LR from the lexicon is that there can be other exponents in the lexicon corresponding to these features in the LR, but not selected. For instance, in Moroccan Arabic, the exponent /-k/ expresses second person singular (Harrell 1962:134), and therefore a broader picture of the lexicon can be illustrated as follows:

(8)

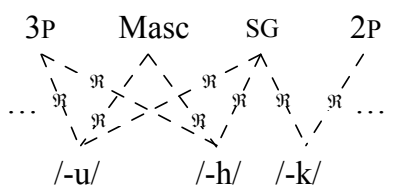

Nevertheless, the exponent/-k/ does not appear in the LR shown in (7a). Though it is also an exponent of the feature $\{$ SINGULAR\}, it will introduce some extra meaning which is not intended (i.e. second person). The selection of proper LR based on the meaning needs extra mechanism, and I assume that this process takes place at a different level, which is not the main focus of this paper. 
3.2 i-Gen function Second, I propose that there are two GEN functions, a more restrictive one, iGEN ('i' for 'intermediate') and the conventional GEN in Standard OT (Prince and Smolensky 1993/2004) ${ }^{1}$. In general, i-GEN accesses to the Lexical Representation (LR), i.e. the structures shown in (7) and (8), and generate a set of forms containing various permutations of the exponents provided by LR, which I will call the Exponent-Chosen Representation (ER) (cf. Unification-GEN and Enriched Input in Sprouse 1997). For the familiar GEN in standard OT (which I will simply use GEN thereafter), it takes ER as the input and generates various output candidates, which I will refer to as Surface Representation (SR). The i-GeN function is relatively more restrictive in the sense that it can only select which exponent or exponents will appear at ER level, and combine them in different ways if there is more than one. The formal definition of i-GEN function is given in (9):

\section{i-GEN function}

a. The Lexical Representation (LR) includes both morphosyntactic information and corresponding exponents.

b. Let $\mathrm{F}$ be a morphosyntactic feature which stands in correspondence with a set of exponents $\mathrm{E}=\left\{/ \mathrm{e}_{1}, \mathrm{e}_{2}, \ldots \mathrm{e}_{\mathrm{n}} /\right\}(\mathrm{n} \geq 1)$, and for each $\mathrm{e}_{\mathrm{i}} \in \mathrm{E}(1 \leq \mathrm{i} \leq \mathrm{n})$, there is $\mathrm{F} \mathfrak{R} \mathrm{e}_{\mathrm{i}}$.

c. Let E' be the set of ERs generated by i-GEN

$$
\text { For } \begin{aligned}
\mathrm{E}= & \left\{\mathrm{e}_{1}, \mathrm{e}_{2}, \ldots \mathrm{e}_{\mathrm{i}} \ldots \mathrm{e}_{\mathrm{n}} /\right\} \\
\mathrm{E}, & \mathrm{i}-\operatorname{GEN}(\mathrm{E}) \\
= & \mathrm{i}-\mathrm{GEN}\left(/ \mathrm{e}_{1}, \mathrm{e}_{2}, \ldots \mathrm{e}_{\mathrm{i}} \ldots \mathrm{e}_{\mathrm{n}} /\right) \\
= & \left\{\mathrm{e}_{1}, \mathrm{e}_{2} \ldots \mathrm{e}_{\mathrm{n}}\right\} \cup\left\{\left(\mathrm{e}_{1}+\mathrm{e}_{2}\right),\left(\mathrm{e}_{1}+\mathrm{e}_{3}\right) \ldots\left(\mathrm{e}_{1}+\mathrm{e}_{\mathrm{n}}\right),\left(\mathrm{e}_{2}+\mathrm{e}_{1}\right),\left(\mathrm{e}_{2}+\mathrm{e}_{3}\right) \ldots\left(\mathrm{e}_{2}+\mathrm{e}_{\mathrm{n}}\right) \ldots\right. \\
& \left.\left(\mathrm{e}_{\mathrm{n}}+\mathrm{e}_{\mathrm{n}-1}\right)\right\} \cup \ldots \cup\left\{\left(\mathrm{e}_{1}+\mathrm{e}_{2}+\ldots+\mathrm{e}_{\mathrm{n}}\right) \ldots\left(\mathrm{e}_{\mathrm{n}}+\mathrm{e}_{\mathrm{n}-1}+\ldots+\mathrm{e}_{1}\right)\right\} \cup \varnothing .
\end{aligned}
$$

d. The total number of the elements of set E' will be $P_{n}^{1}+P_{n}^{2}+\ldots+P_{n}^{n}+1$

The function described in (9) can be summarized as follows. For a set of exponents E, the function i-GEN examines all its subsets (including $\varnothing$ ) and generates the permutations on all the elements of each subset. To better illustrate the idea, suppose a feature $\mathrm{F}$ has three corresponding exponents $\left\{/ \mathrm{e}_{1}, \mathrm{e}_{2}, \mathrm{e}_{3} /\right\}$ in LR, and the set E' generated by i-GEN is given in (10):

$$
\begin{aligned}
& i-\operatorname{GEN}\left(/ \mathrm{e}_{1}, \mathrm{e}_{2}, \mathrm{e}_{3} /\right) \\
& \mathrm{E}^{\prime}=\left\{\begin{array}{ccccc}
P_{3}^{1} & P_{3}^{2} & P_{3}^{3} & 1 & \text { total } \\
& \mathrm{e}_{1}+\mathrm{e}_{2} & \mathrm{e}_{1}+\mathrm{e}_{2}+\mathrm{e}_{3} & \\
\mathrm{e}_{1} & \mathrm{e}_{1}+\mathrm{e}_{3} & \mathrm{e}_{1}+\mathrm{e}_{3}+\mathrm{e}_{2} & \\
\mathrm{e}_{2} & \mathrm{e}_{2}+\mathrm{e}_{1} & \mathrm{e}_{2}+\mathrm{e}_{1}+\mathrm{e}_{3} & \\
\mathrm{e}_{3} & \mathrm{e}_{2}+\mathrm{e}_{3} & \mathrm{e}_{2}+\mathrm{e}_{3}+\mathrm{e}_{1} & \\
& \mathrm{e}_{3}+\mathrm{e}_{1} & \mathrm{e}_{3}+\mathrm{e}_{1}+\mathrm{e}_{2} & \\
& \mathrm{e}_{3}+\mathrm{e}_{2} & \mathrm{e}_{3}+\mathrm{e}_{2}+\mathrm{e}_{1} &
\end{array}\right\} 16
\end{aligned}
$$

Different from the GEN in Mascaró (2007) and the U-GEN in Sprouse (1997), one special property of the iGEN here is that it allows the generation of an intermediate representation with all the exponents provided in the LR. Take Lower Jubba Maay for example, since \{PLURAL\} corresponds to two exponents in LR (recall 7b), i-GEN can create a set of ERs (E') including 'mukulal-o', 'mukulal-yal', 'mukulal-o-yal', 'mukulal-yal$\boldsymbol{o}$ ' and 'mukulal- $\varnothing$ ' (suppose the stem is mukulal, 'cat'). Therefore, there is an opportunity for the multiple exponence form 'mukulal-o-yal' to occur. After the generation of a set of ERs, GEN takes each ER as the input and generates a set of SRs, which are the same as the output candidates in Standard OT.

3.3 Exponence constraints Based on the proposals above, the LR may involve one-to-many mapping between $\mathrm{M}$ information and $\mathrm{P}$ information, and i-GEN operates on LR and generates a set of ERs. In (11) below, it is shown that two GEN functions operate on different stages, resulting in two levels of

\footnotetext{
${ }^{1}$ See Sprouse (1997) for a similar proposal of two GEN functions, and Orgun and Sprouse (2007) for the discussion of the intermediate representation.
} 
mapping, i.e. LR-ER (LE) mapping and ER-SR (ES) mapping:

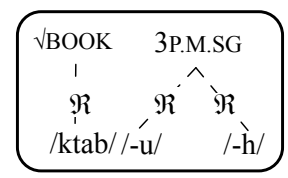

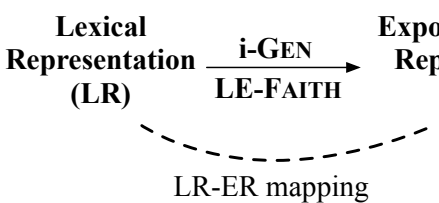

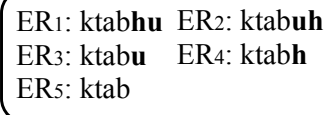

Exponent-Chosen
Representation (ER)

$$
\text { (IO-FAITH) }
$$

$\mathrm{ER}_{1} \rightarrow$ SRs: ktabhu, ktabu, ktab ...

$\mathrm{ER}_{2} \rightarrow$ SRs: ktabuh, ktabh,ktab ...

$\mathrm{ER}_{3} \rightarrow$ SRs: ktabu, ktab, ktau ...

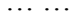

Surface

Representation

(SR)

Suppose the LR contains the exponent of the stem (/ktab/) and the exponents of $3 p . m . s g(/-\mathrm{u} /$ and $/-\mathrm{h} /)$, and i-GEN operates on LR, generating five ERs. Then, all the ERs will be taken by GEN and the SRs will be generated (i.e. output candidates). The mappings in (11) will be evaluated by different faithfulness constraints, in parallel. For the ES mapping, it is the same as the familiar input-output (IO) mapping, and therefore it is evaluated by IO-FAITH constraints. In terms for LE mapping, I propose the following faithfulness constraint which maximally preserves all the exponents provided by lexical representation for feature F. The definition of the exponence constraint is in (12).

\section{(12) MAX- $\forall \mathbf{L E}(\mathbf{F})$ :}

All the phonological information provided in LR must be preserved in ER. (Spell out everything.)

Further, another similar constraint is proposed as the last resort to spell out at least some exponents, which is similar to the function of REALIZEMorPhEME (e.g. Samek-Lodovici 1993, Gnanadesikan 1997, Walker 1998, among others, cf. Kurisu 2001, Walker and Feng 2004):

(13) MAX-ヨLE(F):

Some of the phonological information provided in LR must be preserved in ER. (Spell out something.)

The proposals above can be summarized by the tableau in (14), demonstrating the proposed mappings and the violation profile of the constraints:

\begin{tabular}{|c|c|c|c|c|c|}
\hline & $\begin{array}{c}\sqrt{\text { ERROR }} \\
\text { । } \\
\mathfrak{R} \\
\text { ' } \\
/ \mathrm{xt}^{\mathrm{P}} \mathrm{a} /\end{array}$ & $\begin{array}{c}\stackrel{\wedge}{\text { 3P.M.SG }} \underset{R}{\wedge} \\
/-\mathrm{h} / \mathrm{I} / \mathrm{u} /\end{array}$ & $\begin{array}{c}\text { MAX- } \\
\forall \text { LE(3P.M.SG) }\end{array}$ & $\begin{array}{c}\text { MAX- } \\
\text { ヨLE(3P.M.SG) }\end{array}$ & MAX-IO \\
\hline a. & $x t^{\text {S}} a h u$ & $x t^{\mathrm{S}} \mathrm{a} \cdot \mathrm{hu}$ & & & \\
\hline b. & $x t^{\text {}} a h u$ & $x t^{\complement} a h$ & & & $*$ \\
\hline c. & $x t^{\mathrm{G}}$ ahu & $x t^{\text {S }}$ a.u & & & $*$ \\
\hline d. & $\mathrm{xt}^{\mathrm{S}}$ auh & $x t^{\mathrm{f}}$ a.uh & & & \\
\hline e. & $\mathrm{xt}^{\mathrm{S}}$ auh & $x t^{\mathrm{S}}$ a.u & & & $*$ \\
\hline f. & $x t^{\complement}$ auh & $x t^{\mathrm{S}} \mathrm{a}$ & & & $* *$ \\
\hline g. & $x t^{\mathrm{f}} a h$ & $x t^{\mathrm{f}} a \mathrm{~h}$ & $*$ & & \\
\hline h. & $x t^{\mathrm{f}} \mathrm{ah}$ & $x t^{\mathrm{f}} \mathrm{a}$ & $*$ & & $*$ \\
\hline i. & $\mathrm{xt}^{\mathrm{S}} \mathrm{au}$ & $x t^{\mathrm{S}}$ a.u & $*$ & & \\
\hline j. & $\mathrm{xt}^{\mathrm{S}} \mathrm{au}$ & $x t^{\mathrm{C}} a$ & $*$ & & $*$ \\
\hline $\mathrm{k}$. & $x t^{\mathrm{S}} a$ & $x t^{\mathrm{S}} \mathrm{a}$ & $* *$ & $*$ & \\
\hline
\end{tabular}


In the tableau above, the LR is listed at the top left corner, containing all the required morphosyntactic and phonological information. The i-GEN function takes the LR and generates a set of ERs that include all possible combinations of the exponents, shown in the first column below the LR, while Gen operates on each ER and generates sets of SRs. One ER produced by i-GEN (e.g. $x t^{\mathrm{f}}$ ahu in (20)) can have an infinite number of corresponding SRs, as in the original mechanism in Optimality Theory. Again, the evaluation of LE-FAITH is between the LR and the ER, while the ES-FAITH (IO-FAITH) is evaluated between the ER and the SR.

With this proposal, we can evaluate IO-FAITH constraints straightforwardly. The proposal also suggests that the interaction between the LE-FAITH constraints and markedness constraints can give rise to different types of exponence: PCSA or ME, since now there is possibility to generate candidates with all the exponents provided in the lexicon (e.g. 'mukulal-o-yal'). The utility of this proposal will be further demonstrated by analyzing the data of Lower Jubba Maay in the following section.

\section{The analysis: exponence constraints in action}

This section demonstrates the utility of the proposal by showing the analysis of Lower Jubba Maay. Due to the limitation of space, the data from Moroccan Arabic and Tamazight Berber will not be discussed in this section.

The data from Lower Jubba Maay in (3) and (4) demonstrates both properties of PCSA and multiple exponence. First, the data shows that phonological optimality plays a role in the selection of the markers, i.e. the marker $-o$ is not allowed after vowel-final nouns, which suggests the high-ranking of NOHIATUS (McCarthy 1993). Second, for the consonant-final nouns, taking mukulal ('cat') for example, the plural form can be mukulal-o, mukulal-yal or mukulal-o-yal, the last of which is multiple exponence. In terms of the plural markers, -yal is viewed as the default marker (Paster 2010, Caballero and Inkelas 2013, Harris 2017). In the analysis of Caballero and Inkelas (2013:131), since -yal is able to 'combine with any type of input noun' and 'has a larger phonological size', it is thus viewed as a 'strong exponent' while - $O$ is treated as a 'weak exponent', which result in different weights of the markers. Based on these claims, I will modify the constraint PRIORITY (Mascaró 2007:726) to ensure the preference for the marker -yal:

\section{(15) Priority (yal > o)}

Assign a violation mark for every exponent that is not the prioritized one in the surface (realize the strong exponent).

The constraint PRIORITY is originally proposed in Mascaró (2007:726) to respect lexical ordering of allomorphs. In the current analysis, the modified definition is satisfied by the form only containing the strong affix -yal such as mukulal-yal. In contrast, forms like mukulal-o or mukulal-o-yal will incur violation of this constraint, since an undesirable weak affix is contained in these outputs.

However, the data also shows that the position of -yal is always the outer one, and the form *mukulalyal-o is not attested. Paster (2010) suggests that the default exponent in multiple exponence should be the outermost, and therefore I propose an alignment constraint (McCarthy and Prince 1993) to capture this fact:

(16) Align([yal $\left.]_{\text {af }}, \mathbf{R}, \operatorname{PrWd}, \mathbf{R}\right)$

Align the right edge of the affix $-y a l$ with the right edge of the prosodic word. (-yal should be the outer affix)

With the constraints above, for a vowel-ending noun, the tableau is given in (17). 
(17)

\begin{tabular}{|c|c|c|c|c|c|c|c|c|c|}
\hline & & $\begin{array}{c}\sqrt{ } \text { BRIDGE } \\
\vdots \\
\mathfrak{R} \\
\vdots \\
\text { /buundo/ }\end{array}$ & 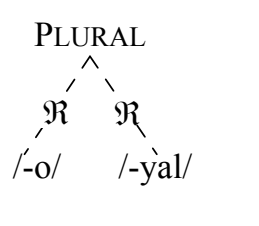 & 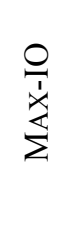 & 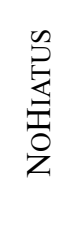 & 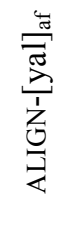 & 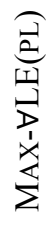 & \begin{tabular}{l}
$\overleftarrow{S}$ \\
0 \\
0 \\
\hdashline \\
$Z$
\end{tabular} & 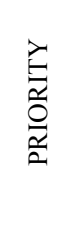 \\
\hline 5 & a. & buundo-yal & buun.do.yal & & & & 1 & 1 & \\
\hline & b. & buundo-o & buun.do.o & & $1 \mathrm{~W}$ & & 1 & 2 & $1 \mathrm{~W}$ \\
\hline & c. & buundo-o & buun.do & $1 \mathrm{~W}$ & & & 1 & 1 & $1 \mathrm{~W}$ \\
\hline & d. & buund-yal-o & buun.do.ya.lo & & & $1 \mathrm{~W}$ & & 1 & 1 \\
\hline
\end{tabular}

In (17), only (17a) can be the winner. The candidate (17b) causes hiatus while (17d) does not make the default marker -yal the outermost one. For (17c), it violates MAX-IO.

When it comes to consonant-final nouns, the variation can be produced through partially ordered constraints (Anttila 1997). Three constraints, MAX- $\forall$ LE(PL), NoCODA and PRIORITY are unordered, giving rise to three possible outputs. The tableau in (18) gives the violation profile of the candidates, and the rankings that yield different outputs are shown in (19).

mukulal-o, NoCODA $>>$ MAX- $\forall$ LE(PL), PRIORITY

\begin{tabular}{|c|c|c|c|c|c|c|c|c|}
\hline & $\begin{array}{c}\sqrt{ } \text { CAT } \\
\vdots \\
\mathfrak{R} \\
\vdots \\
\text { /mukulal/ }\end{array}$ & 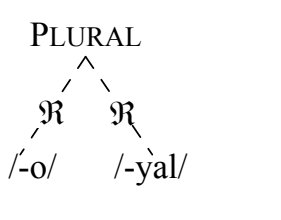 & 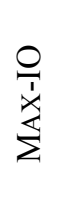 & 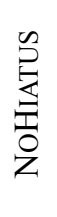 & 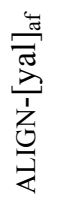 & 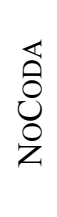 & 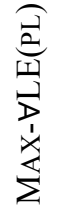 & 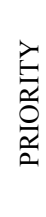 \\
\hline a. & mukulal-o & mu.ku.la.lo & & & & & $*$ & $*$ \\
\hline b. & mukulal-yal & mu.ku.lal.yal & & & & $* *$ & $*$ & \\
\hline c. & mukulal-o-yal & mu.ku.la.lo.yal & & & & $*$ & & $*$ \\
\hline d. & mukulal-yal-o & mu.ku.lal.ya.lo & & & $*$ & $*$ & & $*$ \\
\hline
\end{tabular}

(19)

\begin{tabular}{|c|c|c|}
\hline Ranking & outputs & note \\
\hline $\begin{array}{l}\text { a. MAX-IO, NoHIATUS, ALIGN-[yal }]_{\mathrm{af}}, \\
>>\text { NOCODA }>>\text { MAX- } \forall \mathbf{L E}(\mathbf{P L}), \text { PRIORITY }\end{array}$ & $\begin{array}{l}\text { buundo-yal } \\
\text { mukulal-o }\end{array}$ & \multirow{2}{*}{ ME blocked } \\
\hline $\begin{array}{l}\text { b. MAX-IO, NOHIATUS, ALIGN-[yal }]_{\mathrm{af}}, \\
\text { >> PRIORITY >> MAX- } \forall \text { LE(PL), NoCODA }\end{array}$ & $\begin{array}{l}\text { buundo-yal } \\
\text { mukulal-yal }\end{array}$ & \\
\hline $\begin{array}{ll}\text { c. } & \text { MAX-IO, NoHiATUS, ALIGN-[yal }]_{\mathrm{af}}, \\
& >\text { MAX- } \forall \mathbf{L E}(\mathbf{P L})>>\text { NOCODA, PRIORITY }\end{array}$ & $\begin{array}{l}\text { buundo-yal } \\
\text { mukulal-o-yal }\end{array}$ & ME allowed \\
\hline
\end{tabular}

Based on the discussion above, the optional multiple exponence in Lower Jubba Maay can be generated via freely ranked MAX- $\forall \mathrm{LE}(\mathrm{PL})$ constraint, as well as its interaction with other constraints. Above all, the crucial idea is that when MAX- $\forall \mathrm{LE}(\mathrm{PL})$ is highly ranked, multiple exponence is allowed, and when MAX$\forall \mathrm{LE}(\mathrm{PL})$ is dominated by other constraints, multiple exponence is blocked.

Though the importance of MAX- $\exists \mathrm{LE}(\mathrm{F})$ is not reflected in this case, it is crucial in allomorph selection, as will be shown in the next section.

\section{Typological predictions}

In order to test the typology, I use a hypothetical language which is similar to Moroccan Arabic. In this language, an affix morpheme $\mathrm{F}$ is supposed to have two exponents, /-tel/ and /-is/. The marker/-is/ occurs after consonant-final stem while /-tel/ appears elsewhere, such as [bad-is] and [bada-tel]. This distribution 
can be captured simply by ONSET and NOCODA:

(20)

\begin{tabular}{|c|c|c|c|c|c|}
\hline & $\begin{array}{c}\sqrt{ } \text { BADA } \\
I \\
\mathfrak{R} \\
1 \\
\text { /bada//. }\end{array}$ & $\begin{array}{l}\mathrm{F} \\
\hat{\aleph}_{\mathfrak{R}} \\
1 / \text {-is/2 }\end{array}$ & FAITH-IO & ONSET & NoCODA \\
\hline 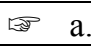 & /bada-tel/ & [ba.da.tel] & & & 1 \\
\hline b. & /bada-is/ & [ba.da.is] & & $1 \mathrm{~W}$ & $\mathrm{~L}$ \\
\hline
\end{tabular}

(21)

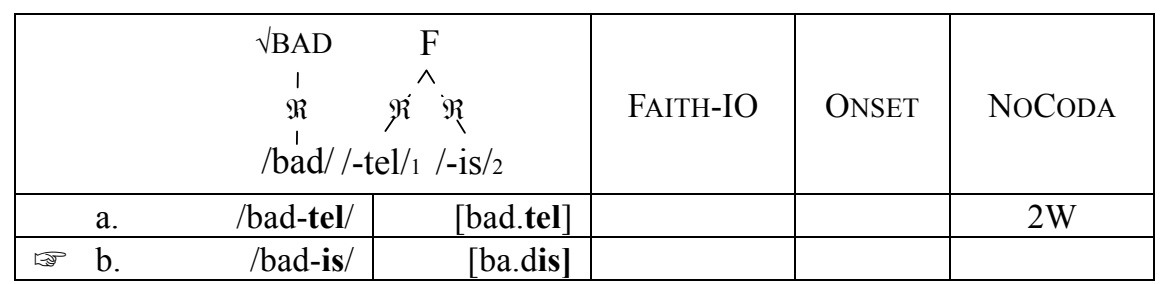

Under the proposal in section 2, there can be also outputs containing both markers, such as [bad-tel-is] ${ }^{2}$, and it is also possible to generate candidates such like [bada- $\mathrm{t}_{1} \mathrm{es}_{2}$ ], where a portion of each exponent is realized. The relevant constraints include MAX- $\exists$ LE(F), I-CONTIG ${ }^{3}$, MAX-IO, ONSET, *STRUC- $\sigma$, NoCODA, $\operatorname{MAX}-\forall \operatorname{LE}(\mathrm{F})$.

By using the constraints above, the typological predictions are tested by OT-Help (Staubs et al. 2010). The constraints and candidates can potentially give rise to 121 different grammars, while 15 of them are possible. Among the 15 grammars, I will temporarily exclude those where MAX-IO or I-CONTIG (or both) are not ranked at the top tier (10 out of 15), and the rest grammars are shown in (22)

(22) Typological predictions (the winners are listed above each grammar)

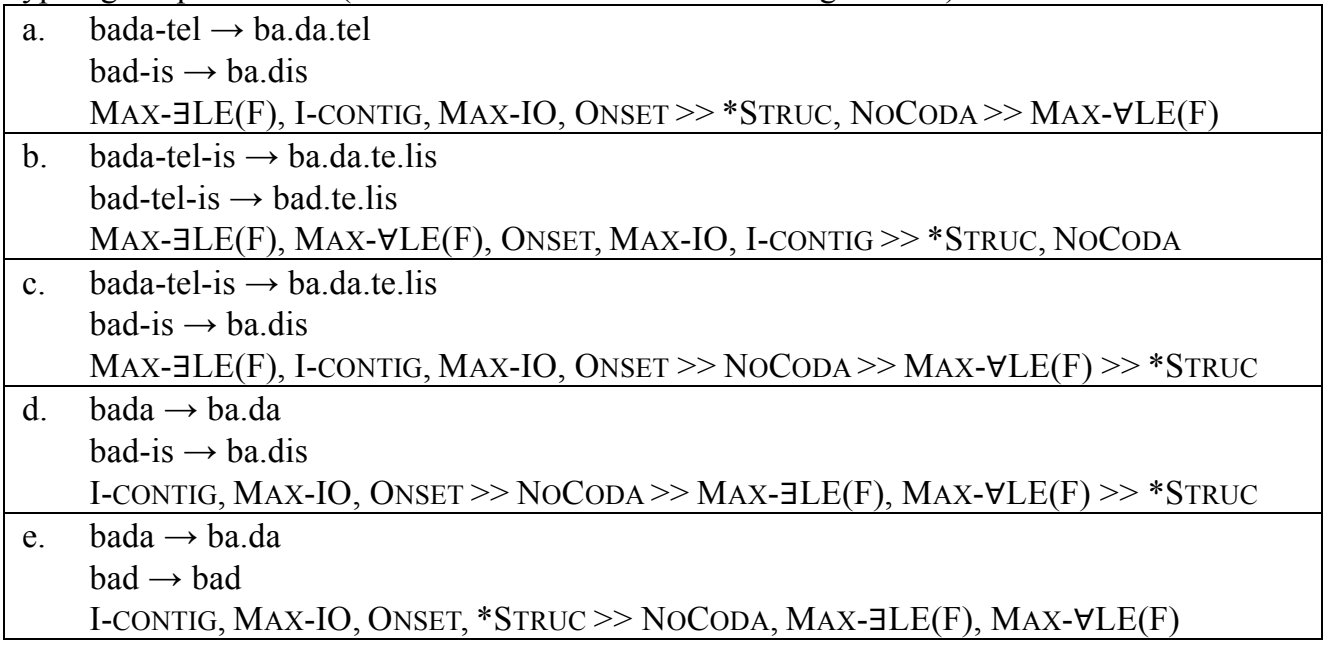

Among the five grammars above, (22a) is the one that selects the allomorphs via TETU, the same as Moroccan Arabic, and the constraint MAX- $\exists \mathrm{LE}(\mathrm{F})$ is important since it ensures the realization of one exponent. In (22b), both [ba.da.te.lis] and [bad.te.lis] have multiple exponence, which is similar to the second person conjugation in Tamazight Berber, where multiple exponence is obligatory and consistent. For (22c),

2 The order of the affixes is not a major issue in this section.

${ }^{3}$ I-CONTIG: no deletion of elements internal to the input string (McCarthy and Prince 1995:123). 
[ba.da.te.lis] exhibits multiple exponence while [bad-is] only selects one marker due to the requirement of wellformedness, which resembles Lower Jubba Maay (as the variation in 19c). In this grammar, MAX- $\forall$ LE(F) is not ranked at the bottom, but the higher-ranked markedness constraint NoCODA prevents *[bad.te.lis], which is comparable to the outputs buundo-yal and mukulal-o-yal in Lower Jubba Maay. For (22d), the ranking NOCODA $>>$ MAX- $\exists L E(F)$ prevents the spell out of feature $F$ in some words, which is a case attested in Bukusu (Odden 2005). In this language, the first person is marked by a placeless nasal $/ \mathrm{N}-/$ but this nasal is not realized when the stem begins with a fricative (e.g. $/ \mathrm{N}$-piima/ $\rightarrow$ [mbiima], but $/ \mathrm{N}$-fuma/ $\rightarrow$ [fuma]). For Bukusu, we can analyze this pattern as $* \mathrm{NC}_{[+ \text {cont] }}>>\mathrm{MAX}-\exists \mathrm{LE}(1 \mathrm{P})$, which is similar to the grammar in (22d). For (22e), it can be viewed as zero affixation. For example, the verb conjugation for the first person singular present tense in English is such a case, e.g. 'I work- $\varnothing$ ', 'I eat- $\varnothing$ ', etc. Finally, there are still 10 more grammars generated by OT-Help that have not been discussed above. All these grammars favor unfaithful input-output mapping, since MAX-IO or I-CONTIG (or both) is ranked low. In general, these grammars are similar to those listed in (22), but the outputs are more unmarked than those in (22), since some faithfulness constraints are ranked lower than markedness.

To sum up, the predicted grammars discussed above can be attested in different languages, which demonstrates the utility of the exponence constraints in predicting various types of exponence. A summary of the types of exponence yielded by different grammars, as well as the attested languages, is given below:

\begin{tabular}{|c|c|c|c|}
\hline & Type of Exponence & Grammar & Language \\
\hline a. & PCSA & $\begin{array}{l}\text { MAX- } \exists \text { LE(F), I-CONTIG, MAX-IO, ONSET }>> \\
* \text { STRUC, NOCODA }>>\text { MAX- } \forall \text { LE(F) }\end{array}$ & $\begin{array}{l}\text { Moroccan Arabic } \\
\{3 \text { P.MASC.SINGULAR }\}\end{array}$ \\
\hline b. & ME & $\begin{array}{l}\text { MAX- } \exists \text { LE(F), MAX- } \forall \text { LE(F), ONSET, MAX-IO, } \\
\text { I-CONTIG }>\text { *STRUC, NOCODA }\end{array}$ & $\begin{array}{l}\text { Tamazight Berber } \\
\text { \{SECOND PERSON\} } \\
\end{array}$ \\
\hline c. & ME for some words & $\begin{array}{l}\text { MAX- } \exists \text { LE(F), I-CONTIG, MAX-IO, ONSET }>> \\
\text { NOCODA }>>\text { MAX- } \forall \text { LE(F) }>>* \text { STRUC }\end{array}$ & $\begin{array}{l}\text { Lower Jubba Maay } \\
\{\text { PLURAL }\end{array}$ \\
\hline d. & $\begin{array}{l}\text { Non-realization for } \\
\text { some words }\end{array}$ & $\begin{array}{l}\text { I-CONTIG, MAX-IO, ONSET }>>\text { NOCODA }>>\text { MAX- } \\
\exists \text { LE(F), MAX- } \forall \text { LE(F) }>>* \text { STRUC }\end{array}$ & $\begin{array}{l}\text { Bukusu } \\
\{1 \text { PERSON PRESENT }\}\end{array}$ \\
\hline e. & Zero realization & $\begin{array}{l}\text { I-CONTIG, MAX-IO, ONSET, *STRUC }>>\text { NOCODA, } \\
\text { MAX- } \exists \text { LE(F), MAX- } \forall \text { LE(F) }\end{array}$ & $\begin{array}{l}\text { English } \\
\{1 \text { PERSON PRESENT }\}\end{array}$ \\
\hline
\end{tabular}

\section{Alternative approach}

In the literature, there are various approaches trying to deal with $\mathrm{ME}$, and some of them are designed to be able to give PCSA and ME a unified account, such as Optimal Interleaving (Wolf 2008, Kimper 2009, McCarthy 2012), Realizational Optimality Theory (Xu 2007, 2016, Xu and Aronoff 2011) and Optimal Construction Morphology (Caballero and Inkelas 2013, Inkelas 2017), and Optimal Construction Morphology will be briefly discussed in this section.

Optimal Construction Morphology (OCM) (Caballero and Inkelas 2013, Inkelas 2017) is a recent morphological model which is incremental and serial. OCM is a theory of morphology that selects the optimal combination of lexical constructions to best achieve a target meaning (Caballero and Inkelas 2013:104). In this model, morphs are spelled out incrementally toward the target meaning, and one step can only select one morph, which is similar to the idea of Harmonic Serialism (McCarthy 2008). One advantage of OCM mentioned by Caballero and Inkelas (2013) is that multiple exponence can be either allowed or blocked without resorting to certain stipulated markedness constraints such like *FEATURE SPLIT (Xu 2007). In OCM, there are two sources of multiple exponence. First, multiple exponence can make the candidate closer to wordhood (BEWORD), and second, multiple exponence can strengthen a weak exponent (Caballero and Inkelas 2013:124). In their analysis of Lower Jubba Maay, -yal is treated as a strong affix and assigned value 1.0 while $-o$ is a weak affix with a value of 0.5 . Therefore, mukulal-o-yal is better than mukulal-o in that the previous one is 'stronger' and enforces the exponence, though introducing more marked structures (ONSET, NOCODA, NoHiatus, etc.).

However, one major difference between OCM and the current approach is that OCM implements a serial analysis while the current one uses parallel evaluation. Regarding the serial analysis, one concern is that the 
look ahead effect of certain allomorph selection would pose a problem for the serial construction. For example, Wolf (2008) discusses the look ahead effect in allomorph selection by using a hypothetical language, where the gender marker can be realized as $-z a$ or $-x o f$ in ROOT-GENDER-NUMBER sequence and the actual selection depends on the phonological context of the peripheral marker (e.g. /peto-xof-u/ but */peto-za-u/), and this type of allomorph selection can be hardly predicted by Harmonic Serialism. Nevertheless, as a newly-developed model, the evaluation of OCM remains an open question and needs further discussion.

\section{Closing remarks}

In sum, this paper deals with some theoretical and analytical issues raised by the phenomena that involve one-to-many mapping between morphosyntactic information and phonological representations, mainly including phonologically conditioned suppletive allomorphy and multiple exponence, and these issues can be addressed with the proposed mechanism. Finally, some representational and analytical issues raised by the cases that involve the arbitrary preference as well as nonconcatenative morphology need further investigation.

\section{References}

Anderson, Stephen R. 2001. On some issues on morphological exponence. In G.Booij \& J. van Marle (eds.), Yearbook of morphology 2000. 1-17. Dordrecht: Kluwer.

Anttila, Arto. 1997. Deriving variation from grammar. In Frans Hinskens, Roeland van Hout \& Leo Wetzels (eds), Variation, Change and Phonological Theory. 35-68. Philadelphia, PA: John Benjamins.

Caballero, Gabriela and Alice C. Harris. 2012. A working typology of multiple exponence. In Kiefer, Ferenc, Mária Ladányi, and Péter Siptár (eds.) Current issues in morphological theory:(Ir)regularity, analogy and frequency. 163188. Amsterdam: John Benjamins Publishing Co.

Caballero, Gabriela and Sharon Inkelas. 2013. Word construction: tracing an optimal path through the lexicon. Morphology 23(2). 103-143.

Carstairs, Andrew. 1988. Some implications of phonologically-conditioned suppletion. In Geert Booij and Jaap van Marle (eds). Yearbook of morphology 1988, 67-94. Dordreht: Foris.

Carstairs, Andrew. 1990. Phonlogically conditioned suppletion. In Wolfgang U. Dressler, Hans C. Luschütsky, Oskar E. Pfeiffer and John R. Rennison (eds). Contemporary Morphology, 17-23. Berlin: Mouton de Gruyter.

Gnanadesikan, Amalia. 1997. Phonology with Ternary Scales. PhD dissertation, University of Massachusetts, Amherst.

Halle, Morris. 1997. Distributed Morphology: Impoverishment and fission. In Benjamin Bruening, Yoojung Kang and Martha McGinis (eds). MIT Working Papers in Linguistics 30: PF: Papers at the Interface, 425-449. Cambridge, MA: MIT Working Papers in Linguistics.

Halles, Morris and Marantz, Alec. 1993. Distributed Morphology and the pieces of inflection. In Kenneth Hale and Smuel Jay Keyser (eds). The View from Building 20: Essays in Linguistics in Honor of Sylvain Bromberger. 111-176. Cambridge, MA: MIT Press.

Harrell, Richard S. 1962. A Short Reference Grammar of Moroccan Arabic. Georgetown University Press.

Harris, Alice C. 2017. Multiple Exponence. New York: Oxford University Press.

Inkelas, Sharon. 2017. The directionality and locality of allomorphic conditioning in Optimal Construction Morphology. In Vera Gribanova and Stephanie S. Shih (eds). The Morphosyntax-Phonology Connection: Locality and Directionality at the Interafce. 285-324. New York: Oxford University Press.

Kimper, Wendell. 2009. Constraints on what's not there: the role of serial derivations in subtractive truncation. Talk presented at HUMDRUM.

Kiparsky, Paul. 2005. Blocking and periphrasis in inflectional paradigms. In Geert Booij and Jaap van Marle (eds). Yearbook of Morphology 2004. 113-136. Dordrecht: Springer.

Kurisu, Kazutaka. 2001. The phonology of morpheme realization. Ph.D. dissertation. University of California Santa Cruz.

Mascaró, Joan. 1996. External sllomorphy as emergence of the unmarked. In Jacques Durand and Bernard Laks (eds). Current Trends in Phonology: Models and Methods, 473-483. Salford: European Studies Research Institute, Uniersity of Salford.

Mascaró, Joan. 2007. External allomorphy and lexical representation. Linguistic Inquiry 38(4). 715-735.

Matthews, Peter H. 1991. Morphology ( $2^{\text {nd }}$ ed.). New York: Cambridge University Press.

McCarthy, John J. 1993. A case of surface constraint violation. Canadian Journal of Linguistics/Revue canadienne de linguistique 38(2). 169-195.

McCarthy, John J. 2008. The gradual path to cluster simplification. Phonology 25. 271-319.

McCarthy, John J. 2012. Pausal phonology and morpheme realization. In Tony Borowsky, Shigeto Kawahara, Takahito shinya \& Mariko Sugahara (eds.), Prosody matters: Essays in honor of Lisa Selkirk. London: Equinox. 
McCarthy, John J. and Alan Prince. 1993. Generalized alignment. In Geert Booij \& Jaap van Marle (eds). Yearbook of Morphology 1993. 79-153. Dordrecht: Kluwer.

McCarthy, John J. and Alan Prince. 1995. Faithfulness and reduplicative identity. In Jill N. Beckman, Laura Walsh Dickey and Suzanne Urbanczyk (eds). University of Massachusetts Occasional Papers in Linguistics 18: Papers in Optimality Theory. 249-384. Amherst, MA: GLSA.

Nevins, Andrew. 2011. Phonologically-Conditioned Allomorph Selection. In Colin Ewen, Elizabeth Hume, Marc van Oostendorp and Keren Rice (eds). The Blackwell Companion to Phonology. Wiley-Blackwell.

Noyer, Robert. 1992. Features, positions and affixes in autonomous morphological structure. PhD dissertation. Boston, MA: Massachusetts Institute of Technology.

Odden, David. 2005. Introducing Phonology. New York: Cambridge University Press.

Orgun, Orhan, and Ronald Sprouse. 2007. A freer input: Yowlumne opacity and the Enriched Input Model. In Sylvia Blaho, Patrik Bye, Martin Kramer (eds.) Freedom of Analysis. The Hague: Mouton de Gruyter.

Paster, Mary. 2006. Aspects of Maay phonology and morphology. Studies in African linguistics 35(1). 73-120.

Paster, Mary. 2010. Optional multiple plural marking in Maay. In Franz Rainer, Wolfgang U. Dressler, Dieter Kastovsky and Hans C. Luschütsky (eds). Variation and Change in Morphology. 177-192. Amsterdam: John Benjamins.

Prince, Alan and Paul Smolensky. 2004[1993]. Optimality Theory: Constraint interaction in Generative Grammar. Malden, MA and Oxford: Blackwell.

Samek-Lodovici, Vieri. 1993. A unified analysis of crosslinguistic morphological gemination. Proceedings of CONSOLE (ROA-149). [Available at http://roa.rutgers.edu/article/view/160]

Sprouse, Ronald. 1997. A case for enriched inputs. Handout of a presentation at TREND 3 (ROA-204). [Available at http://roa.rutgers.edu/article/view/204].

Staubs, Robert, Michael Becker, Christopher Potts, Patrick Pratt, John J. McCarthy \& Joe Pater. 2010. OT-Help 2.0. Software package. Amherst, MA: University of Massachusetts Amherst.

Staubs, Robert. 2011. Operational exponence: Process morphology in Harmonic Serialism. Paper presented at Challenges of Complex Morphology to Morphological Theory, Linguistic Society of America Summer Institute.

Struijke, Caro. 2000. Existential Faithfulness: A Study of Reduplicative TETU, Feature Movement, and Dissimilation. New York: Routledge.

Trommer, Jochen. 2001. Distributed Optimality. PhD dissertation. Potsdam University.

Walker, Rachel. 1998. Nasalization, Neutral Segments, and Opacity Effects. PhD dissertation, University of California, Santa Cruz.

Walker, Rachel. 2000. Nasal reduplication in Mbe affixation. Phonology 17(1). 65-115.

Walker, Rachel \& Bella Feng. 2004. A ternary model of morphology-phonology correspondence. Proceedings of WCCFL, vol. $23,773-786$.

Wolf, Matthew. 2008. Optimal interleaving: Serial phonology-morphology interaction in a constraint-based model. $\mathrm{PhD}$ dissertation. University of Massachusetts, Amherst.

Xu, Zheng. 2007. Inflectional morphology in Optimality Theory. PhD dissertation. State University of New York, Stony Brook.

Xu, Zheng. 2016. The role of morphology in Optimality Theory. In Andrew Hippisley and Gregory Stump (eds.), The Cambridge Handbook of Morphology. Cambridge: Cambridge University Press.

$\mathrm{Xu}$, Zheng and Mark Aronoff. 2011. A Realization Optimality Theory approach to blocking and extended morphological exponence. Journal of Linguistics 47(3). 673-707.

Zoll, Cheryl. 1993. Directionless syllabification and ghosts in Yawelmani. Ms. Berkeley, CA. [Available at http://roa.rutgers.edu/files/28-0000/28-0000-ZOLL-0-0.PDF].

Zoll, Cheryl. 1996. Parsing below the Segment in a Constraint-based Framework. PhD. Dissertation. University of California, Berkeley. 